\title{
Determinación de las condiciones óptimas para la liberación de zoosporas de Spongospora subterranea en bioensayos
}

\author{
Carolina Corrales Puerta ${ }^{1}$, Catalina Zuluaga Amaya ${ }^{1}$, José Miguel Cotes Torres ${ }^{2}$ \& Elena Paola González- \\ Jaimes $^{1}$ \\ ${ }^{1}$ Politécnico Colombiano Jaime Isaza Cadavid, Facultad de Ciencias Agrarias, Cra 48 N.7-151, Medellín, Colombia; \\ ${ }^{2}$ Universidad Nacional de Colombia, Facultad de Ciencias Agropecuarias, Calle 59A No 63-20 Bloque11, Medellín, \\ Colombia
}

Autor para correspondencia: Elena Paola González-Jaimes, e-mail: epgonzalez@elpoli.edu.co

\begin{abstract}
RESUMEN
La sarna polvosa de la papa es causada por Spongospora subterranea f. sp. subterranea, parasito obligado y patógeno del suelo, que afecta el sistema radicular y tubérculos de papa. Igualmente es vector del pomovirus Potato mop-top virus (PMTV). Este organismo posee quistosoros como estructuras de resistencia las cuales le confieren la posibilidad de permanecer en el suelo por años. Este estudio busca determinar bajo que condiciones de temperatura, fuentes de inóculo y sustratos se obtiene una máxima liberación de zoosporas con el fin de utilizar esta metodología en pruebas de infección de S. subterranea. Así se realizaron tres ensayos donde se evaluaron tres fuentes de inóculo (suelo, raíz, tubérculo), tres medios líquidos (agua, extracto de raíz y solución nutritiva) y diferentes temperaturas. Las observaciones fueron realizadas en microscopio con cámara de Neubauer por conteo de zoosporas móviles, con lecturas en el tiempo a partir de las 24 hasta las 120 horas. Se encontró como resultado diferencias significativas en los sustratos empleados para liberación manifestándose mayor liberación de zoosporas en extracto de raíz en temperatura fluctuante de $20-15^{\circ} \mathrm{C}$ a partir de las 24 horas de inoculación hasta las 96 horas.
\end{abstract}

Palabras-clave: Inóculo, quistosoro, sarna polvosa.

\begin{abstract}
Determination of optimal conditions for Spongospora subterranea zoospore release on bioassays

Potato powdery scab is caused by Spongospora subterranea f. sp. subterranea, an obligate parasite and soil-borne pathogen which affects the root system and tubers. It is also a vector of the pomovirus Potato mop-top virus (PMTV). This organism has resistance structures called cystosori which allows it to remain in the soil for years. This study aimed to determine the optimal conditions of temperature, inoculum sources and substrate for zoospore release, for future use in infectivity assays. Three experiments were conducted in which three inoculum sources (soil, roots and tubers), three liquid substrates (water, root extract and nutrient solution) and different temperatures were tested. Observations of mobile zoospores were made in a light microscope equipped with a Neubauer chamber, from 24 until 120 hours after inoculation. Significant differences were found among the different treatments, with the optimal conditions using root extract as inoculum source, temperature between 15 and $20^{\circ} \mathrm{C}$, from 24 until 96 hours after inoculation.
\end{abstract}

Key words: Cystosori, inoculum, powdery scab.

\section{INTRODUCCIÓN}

Spongospora subterranea f. sp. subterranea es un parásito obligado que causa la sarna polvosa de la papa y es además vector del pomovirus Potato mop-top virus (PMTV). Este patógeno del suelo limita la producción de papa de manera importante, llegando a excluir zonas para este cultivo. S. subterranea es un protozoo que pertenece al orden Plasmodiophorales el cual es un grupo monofilético, cuyos miembros tienen en común características como la división nuclear cruciforme, zoosporas con dos flagelos, fase ameboidal, protoplasto multinucleado, plasmodios, parasitismo intracelular obligado y esporas de resistencia en quistes (Karling, 1942; Braselton, 2007). Según Hooker (1980), hay dos fases importantes del ciclo de vida de este patógeno, cada una iniciada por la infección de la célula huésped a través de un plasmodio unicelular. La fase esporogénica se presenta después de la división nuclear, produciendo esporas de pared gruesa, las cuales son altamente resistentes. Cada espora libera una sola zoospora primaria biflagelada, la cual entra en el sistema radical del huésped. En la fase esporangial, el esporangio de paredes delgadas se desarrolla entre células huéspedes, en las cuales se forman ocho zoosporas desde un plasmodio esporangiogineo. Las zoosporas secundarias también son biflageladas y pueden salir del huésped e iniciar otro ciclo de infección.

Los quistosoros son de forma ovoide, color ocre oscuro, con un diámetro de 20 a $80 \mu \mathrm{M}$ con la apariencia de una pelota de golf; las zoosporas poseen 2 flagelos de 
diferente tamaño insertados lateralmente en un ángulo de $180^{\circ}$, el flagelo largo mide entre $0,8-16,4 \mu \mathrm{M}$ y el pequeño entre 0,4-5 $\mu \mathrm{M}$ (Merz, 1993; Alzate et al., 2008)

Las zoosporas pueden ser inducidas al enquistamiento por agentes artificiales, en condiciones de laboratorio puede ser inducida por una alta concentración de químicos o agitación mecánica, pero naturalmente es debido al reconocimiento de un componente de la superficie del huésped (Donaldson \& Deacon 1993). Cruz (2008) afirma que el patógeno permanece en el suelo como esporas de resistencia, que pueden sobrevivir por más de seis años en condiciones adecuadas de temperatura y humedad, que generalmente coinciden con las del cultivo, las esporas de resistencia originan las zoosporas, que infectan los pelos radicales, raíces, y posteriormente a los tubérculos a través de las lenticelas, heridas y yemas. La persistencia de los quistosoros en el suelo y tubérculos hace que la sarna polvosa sea una enfermedad de difícil manejo (Harrison et al., 1997). Estas estructuras de resistencia pueden también sobrevivir al paso por el tracto intestinal de los animales alimentados con tubérculos infectados (Torres, 2002). La prevalencia de socas ha aumentado la contaminación de los suelos por la supervivencia de los quistosoros (Wale, 2000), los cuales se distribuyen en parche, sin embargo el desarrollo de la enfermedad es altamente dependiente de las condiciones ambientales (Lees, 2000).

La enfermedad afecta raíces, estolones y tubérculos. Las raíces de las plantas enfermas muestran agallas o tumores lisos, de 0,5 a $1,5 \mathrm{~cm}$ de tamaño y de forma mas o menos irregular; al inicio las agallas son de color blanquecino y cuando alcanzan la madurez fisiológica se vuelven oscuras, debido al color marrón de las paredes de las estructuras de resistencia (Harrison et al., 1997). El estado de infección radical de S. subterranea durante su ciclo de vida sobre las plantas de papa y posiblemente hospederos alternos, es muy importante para la epidemiología de la sarna polvosa, debido a que la infección radical incrementa rápidamente las zoosporas y esporas de resistencia en los suelos donde crecen las papas y especies hospederas, especialmente si los materiales son muy susceptibles a la infección radical y a la formación de agallas. Según Falloon et al. (2003), aunque algunas variedades que presentan resistencia en los tubérculos son resistentes a la infección en raíces, no siempre es así, en un experimento realizado encontró que de todos los clones evaluados ninguno presentó inmunidad a la infección radical y por lo tanto es la fuente de inóculo mas importante. Lees (2000) plantea que la eficiencia de los bioensayos para la detección de $S$. subterranea en el suelo es variable, pero útil para evaluar razas y su diferencia potencial en patogenicidad.

El objetivo de este trabajo fue evaluar las condiciones óptimas para la liberación de zoosporas en condiciones de bioensayo con el fin de utilizar esta metodología en ensayos posteriores de infección y screening de variedades.

\section{MATERIALES Y MÉTODOS}

Los quistosoros fueron obtenido a partir de suelos y tejidos vegetales (agallas de raíces y pústulas de tubérculos) infectados por el patógeno. Las muestras fueron tomadas en el municipio de la Unión (Antioquia) veredas Vallejuelito, La Cabaña y Mazorcal.

Una vez obtenido el material se procedía a realizar una evaluación macroscópica y microscópica de las muestras. La identificación macroscópica consiste en una caracterización de los síntomas típicos causados por S. subterranea en raíces y tubérculos mientras la microscópica se realizó mediante la observación y cuantificación a través de un microscopio de la presencia de quistosoros en aumentos de 10x y 40x para las diferentes muestras.

\section{Obtención de quistosoros}

La extracción de quistosoros de tres diferentes fuentes a evaluar (suelo, raíz, tubérculo) se realizó de acuerdo a las siguientes metodologías: para la obtención de quistosoros a partir de suelo infectado se utilizó la metodología propuesta por Jaramillo \& Botero (2007) modificada por Alzate et al. (2008), en la cual 1 gr de suelo infectado seco se pasa a través de un juego de tamices entre 250 y 53 micra recogiendo los quistosoros presentes en este último tamiz; para el tubérculo se utilizó la metodología propuesta por Van de Graaf et al. (2005), en la cual se raspa la superficie de los tubérculos infectados, se secan al aire libre durante 48 horas, luego se maceran con el fin de disminuir el tamaño de las partículas y finalmente el material obtenido se pasa por el mismo juego de tamices empleado para suelo.

Las raíces infectadas, se lavan con agua corriente con el fin de retirar los excesos de suelo, posteriormente se retiran las agallas y se secan durante 48 horas al aire libre, se maceran para disminuir el tamaño de las partículas, este material se tamiza y se obtienen los quistosoros.

\section{Conteo y evaluación de la concentración de quistosoros}

De acuerdo con la estandarización de metodología realizada por Alzate et al. (2008), una vez obtenidos los quistosoros de suelo, raíz y tubérculo se efectuó el conteo al microscopio en cámara de Neubauer, se pesó para cada inóculo $0,1 \mathrm{gr}$ en balanza analítica y luego se adicionaron $10 \mathrm{~mL}$ de agua destilada; la solución fue realizada en tubos Falcon de $15 \mathrm{~mL}$. Consecutivamente se desarrollaron 10 lecturas con dos repeticiones en la cámara y con los datos obtenidos se determinó la concentración de quistosoros por gramo de inóculo en cada muestra.

\section{Preparación del extracto de raíz}

La preparación del extracto de raíz se realizó con raíces sanas de papa (Solanum tuberosum), variedad Diacol Capiro, siguiendo la metodología utilizada por Álzate et al. (2008), la cual consiste en lavar las raíces frescas y licuarlas en agua destilada en una relación de 1:10. Este 
procedimiento fue realizado el mismo día del montaje para evitar fermentación en la solución preparada

\section{Preparación de la solución nutritiva}

Se utilizó la solución nutritiva de Hoagland, la cual es empleada para fertilización química de plantas para la propagación de micorrizas arbusculares, siguiendo las indicaciones de Millner \& Kilt (1992).

\section{Tratamientos y diseño experimental}

Para determinar las condiciones necesarias para la liberación de zoosporas, se realizó un ensayo piloto con distribución factorial de $3 \times 4 \times 2$, utilizando tres fuentes de quistosoros, suelo, raíz y tubérculo a una concentración de $1 \times 10^{4}$ quistosoros $/ \mathrm{mL}$, cuatro temperaturas $\left(5,20,25^{\circ} \mathrm{C}\right.$ y temperatura ambiente) y dos sustratos (agua y extracto de raíces). Las evaluaciones se realizaron a las 6, 12, 18, 24, 48, 72, 96 y 120 horas. Para el análisis se utilizó un modelo de medias repetidas en el tiempo.

El segundo ensayo se dividió en dos fases donde se probaron los siguientes tratamientos:

Fase 1: Factoríal $3 \times 2$, tres temperaturas $\left[5-20^{\circ} \mathrm{C}(12\right.$ horas a $5^{\circ} \mathrm{C}$ y el resto de tiempo en $\left.20^{\circ} \mathrm{C}\right), 20-5^{\circ} \mathrm{C}(12$ horas a $20^{\circ} \mathrm{C}$ y el resto de tiempo en $\left.5^{\circ} \mathrm{C}\right)$, y $\left.20-15^{\circ} \mathrm{C}(12 / 12)\right]$, dos sustratos (agua y extracto de raíz), todo el ensayo se hizo con inóculo de suelo.

Fase 2 : Factorial de $4 \times 3 \times 3$, con quatrotemperaturas $\left(10,15,20,25^{\circ} \mathrm{C}\right)$, tres fuentes de inóculos (raíz, suelo, tubérculo) y tres sustratos (agua, solución nutritiva y extracto de raíz)

El tercer ensayo se diseño como un factorial de $5 \times 3 \times 3$, con cinco temperaturas $\left[10-15-20-25^{\circ} \mathrm{C}\right.$ y contraste de $\left.15-20^{\circ} \mathrm{C}(12 / 12)\right]$, tres fuentes de inóculo y tres sustratos. En ambos ensayos se hicieron las evaluaciones a las 24,48 , 72,96 y 120 horas.

\section{RESULTADOS Y DISCUSIÓN}

En el ensayo piloto se determinó que a una temperatura de $5^{\circ} \mathrm{C}$ independiente del sustrato que se utilice no hay liberación, razón por la cual se decide eliminar esta temperatura de los ensayos propuestos. El inicio de la liberación de zoosporas es posterior a 24 horas, así las evaluaciones de 6, 12 y 18 horas fueron eliminadas. Con respecto a la fuente de quistosoros inicialmente no se encontraron diferencias. En la Figura 1 se puede observar que se encontró mayor liberación de zoosporas utilizando extracto de raíces, que en solución nutritiva o en agua, siendo el mejor inóculo el de raíz.

En el segundo ensayo se verificó que los tratamientos de la fase $1,5-20^{\circ} \mathrm{C}$ y $20-5^{\circ} \mathrm{C}$ no presentaban diferencias significativas con los tratamientos de 20 y $5^{\circ} \mathrm{C}$ respectivamente (Figura 2). Con respecto a los tiempos de liberación se observa que casi todos los tratamientos presentaron mayor liberación entre las 48 y las 96 horas, con una disminución a las 120 horas.

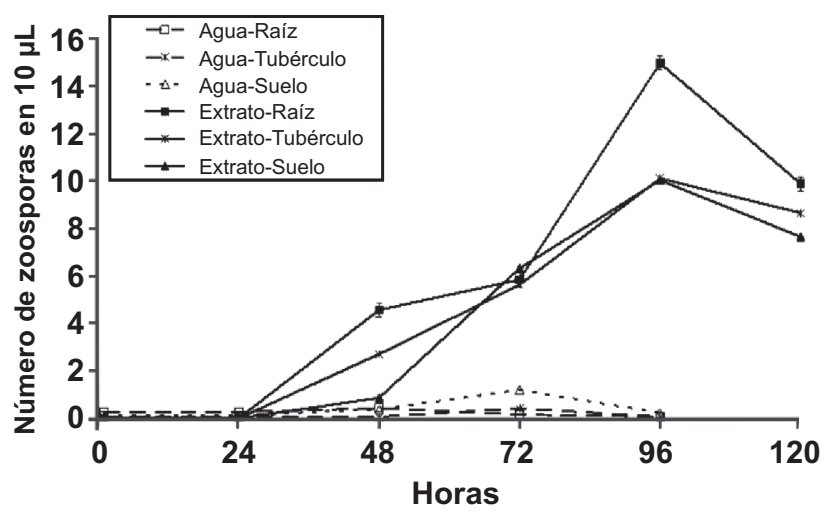

FIGURA 1 - Relación sustrato - fuente de inóculo - tiempo de liberación de zoosporas del ensayo piloto.

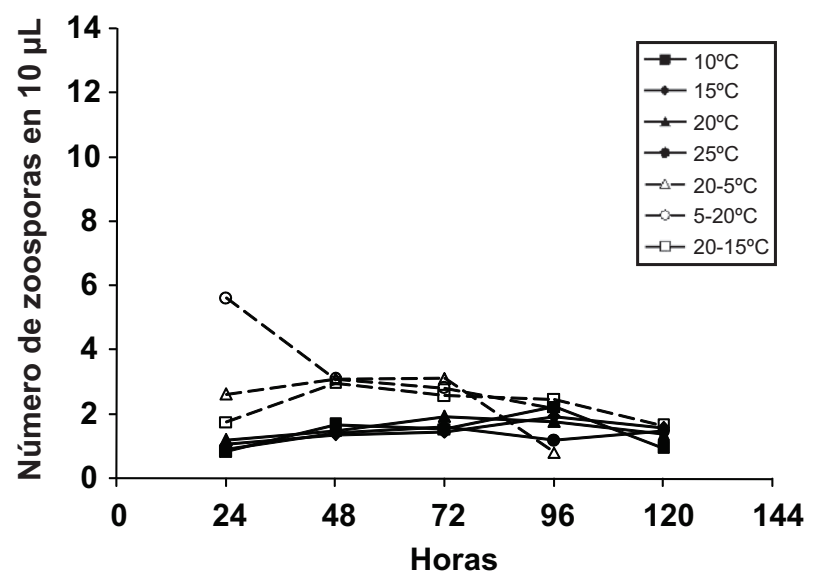

FIGURA 2 - Número de zoosporas liberadas en $10 \mu \mathrm{L}$ de agua con relación al tiempo utilizando los diferentes contrastes de temperatura de la Fase 1 del segundo ensayo.

Los resultados del tercer ensayo (Tabla 1) muestran diferencias significativas en la interacciones triples de sustrato $\times$ inoculo $\times$ tiempo, sustrato $\times$ inoculo $\times$ temperatura $\mathrm{e}$ inóculo $\times$ tiempo $\times$ temperatura. Estas interacciones pueden ser vistas con mayor claridad en la Figura 3, en donde se puede observar que al igual que en el primer ensayo la mejor liberación de zoosporas se obtiene utilizando como sustrato el extracto de raíz y con inóculo obtenido a partir de agallas de raíz. En términos generales en todos los tratamientos la mayor liberación ocurre entre las 48 y las 96 horas, siendo que a las 120 horas aunque aún hay liberación esta es mucho menor. También se puede observar que al utilizar agua y solución nutritiva como sustrato para liberación no hay diferencia significativa siendo mucho menor el número de zoosporas liberadas.

Al finalizar todos los ensayos se realizó un análisis conjunto de los datos de los 3 experimentos (Tabla 2; Figura 4). Se puede ver la confirmación de la tendencia que presentaron los tratamientos en los ensayos independientes. 
TABLA 1 - Prueba de significancia para el efecto de sustrato, inóculo, temperatura y tiempo de inoculación en ensayos 2 y 3 . Resaltado en negrita están los efectos que presentan un valor p menor del 5\%. Subrayado se presenta la interacción de más alto orden que fue significativa $(\alpha=0,05)$

\begin{tabular}{lcccc}
\hline \hline Efecto & \multicolumn{3}{c}{ Prueba de efectos fijos } \\
\cline { 2 - 5 } & $\begin{array}{c}\text { Grados de libertad } \\
\text { numerador }\end{array}$ & $\begin{array}{c}\text { Grados de libertad } \\
\text { denominador }\end{array}$ & Valor F & Valor $\boldsymbol{p}$ \\
\hline Sustrato & 2 & 222,46 & 93,27388 & $<\mathbf{0 , 0 0 1}$ \\
Inóculo & 2 & 212,50 & 10,32593 & $<\mathbf{0 , 0 0 1}$ \\
Sustrato $\times$ inóculo & 4 & 212,28 & 25,91514 & $<\mathbf{0 , 0 0 1}$ \\
Tiempo & 4 & 5,46 & 7,115433 & $\mathbf{0 , 0 2 2 4}$ \\
Sustrato $\times$ tiempo & 8 & 886,89 & 3,483515 & $<\mathbf{0 , 0 0 1}$ \\
Inóculo $\times$ tiempo & 8 & 887,36 & 6,066693 & $<\mathbf{0 , 0 0 1}$ \\
Sustrato $\times$ inóculo $\times$ tiempo & $\underline{16}$ & $\underline{887,28}$ & $\underline{2,227434}$ & $\underline{\mathbf{0 , 0 0 3 7}}$ \\
Temperatura & 6 & 223,35 & 4,915429 & $<\mathbf{0 , 0 0 1}$ \\
Sustrato $\times$ temperatura & 10 & 218,46 & 0,827296 & 0,6027 \\
Inóculo $\times$ temperatura & 8 & 211,21 & 2,776876 & $\mathbf{0 , 0 0 6 1}$ \\
$\underline{\text { Sustrato } \times \text { inóculo } \times \text { temperatura }}$ & $\underline{\mathbf{1 6}}$ & $\underline{211,30}$ & $\underline{\mathbf{1 , 7 0 2 8 8 9}}$ & $\underline{\mathbf{0 , 0 4 7 9}}$ \\
Tiempo $\times$ temperatura & 22 & 814,93 & 1,950837 & $\mathbf{0 , 0 0 5 7}$ \\
Sustrato $\times$ tiempo $\times$ temperatura & 38 & 885,30 & 1,109132 & 0,3015 \\
$\underline{\text { Inóculo } \times \text { tiempo } \times \text { temperatura }}$ & $\underline{32}$ & $\underline{885,84}$ & $\underline{2,538387}$ & $\underline{\mathbf{0 , 0 0 1}}$ \\
Sustrato $\times$ inóculo $\times$ tiempo $\times$ temperatura & 64 & 885,50 & 1,235245 & 0,1072 \\
\hline
\end{tabular}

TABLA 2 - Prueba de significancia para el efecto de sustrato, inóculo, temperatura y tiempo de inoculación en los tres ensayos. Resaltado en negrita están los efectos que presentan un valor $\mathrm{p}$ menor del $5 \%$. Subrayado se presenta la interacción de más alto orden que fue significativa $(\alpha=0,05)$

\begin{tabular}{lcccc}
\hline \hline \multirow{2}{*}{ Efecto } & \multicolumn{4}{c}{ Prueba de efectos fijos } \\
\cline { 2 - 5 } & $\begin{array}{c}\text { Grados de libertad } \\
\text { numerador }\end{array}$ & $\begin{array}{c}\text { Grados de libertad } \\
\text { denominador }\end{array}$ & Valor F & Valor $\boldsymbol{p}$ \\
\hline Sustrato & 2 & 261,10 & 88,98 & $<\mathbf{0 , 0 0 1}$ \\
Inóculo & 2 & 248,97 & 8,90 & $<\mathbf{0 , 0 0 1}$ \\
Sustrato $\times$ inóculo & 4 & 248,76 & 21,95 & $<\mathbf{0 , 0 0 1}$ \\
Tiempo & 4 & 7,61 & 0,80 & 0,5545 \\
Sustrato $\times$ tiempo & 8 & 1013,96 & 3,10 & $\mathbf{0 , 0 0 1 8}$ \\
Inóculo $\times$ tiempo & 8 & 1011,57 & 5,23 & $<\mathbf{0 , 0 0 1}$ \\
Sustrato $\times$ inóculo $\times$ tiempo & $\underline{16}$ & $\underline{1011,61}$ & $\underline{\mathbf{1 , 8 5}}$ & $\underline{\mathbf{0 , 0 2 1 7}}$ \\
Temperatura & 6 & 261,39 & 6,72 & $<\mathbf{0 , 0 0 1}$ \\
Sustrato $\times$ temperatura & 10 & 256,41 & 2,24 & $\mathbf{0 , 0 1 5 9}$ \\
Inóculo $\times$ temperatura & 8 & 247,77 & 2,17 & $\mathbf{0 , 0 3 0 4}$ \\
Sustrato $\times$ inóculo $\times$ temperatura & 16 & 247,94 & 1,47 & 0,1096 \\
Tiempo $\times$ temperatura & 22 & 1012,01 & 2,85 & $<\mathbf{0 , 0 0 1}$ \\
Sustrato $\times$ tiempo $\times$ temperatura & $\underline{38}$ & $\underline{1011,56}$ & $\underline{2,81}$ & $\leq \mathbf{0 , 0 0 1}$ \\
Inóculo $\times$ tiempo $\times$ temperatura & $\underline{32}$ & $\underline{1011,14}$ & $\underline{2,38}$ & $\leq \mathbf{0 , 0 0 1}$ \\
Sustrato $\times$ inóculo $\times$ tiempo $\times$ temperatura & 64 & 1011,10 & 1,03 & $\mathbf{0 , 4 0 9 7}$ \\
\hline
\end{tabular}




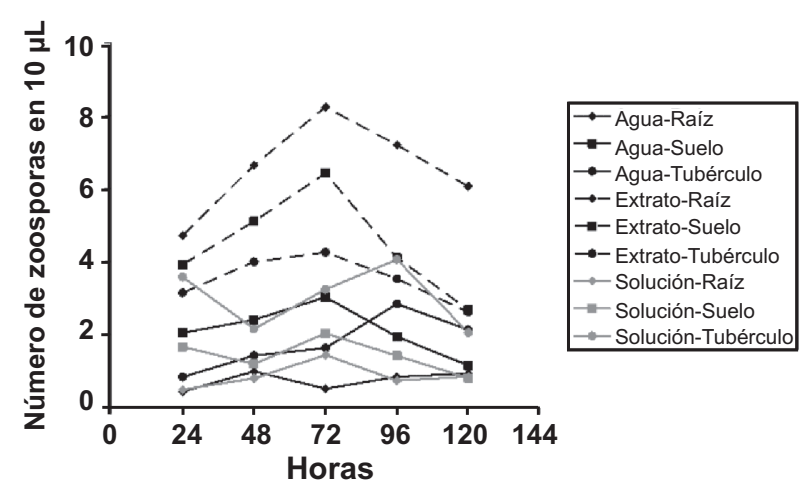

FIGURA 3 - Número de zoosporas liberadas en $10 \mu \mathrm{L}$ de sustrato en la interacción sustrato -inóculo -tiempo para los ensayos 2 y 3.

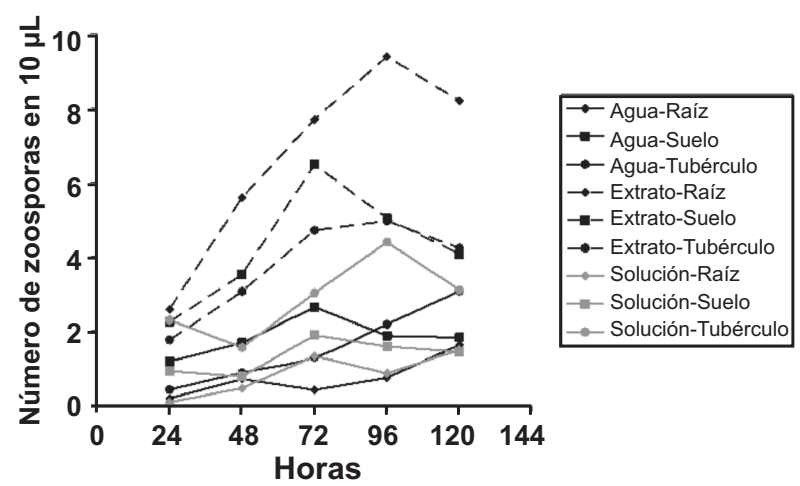

FIGURA 4 - Número de zoosporas liberadas en $10 \mu \mathrm{L}$ de sustrato en la interacción sustrato - inóculo - tiempo para los tres ensayos.

En los tratamientos que involucraron el uso de rampa de temperatura $\left(15-20^{\circ} \mathrm{C}\right.$ por $\left.12 / 12\right)$ se observó una influencia positiva en el número de zoosporas liberadas, lo que indica que los cambios de temperatura que se dan en condiciones de campo favorecen la liberación de zoosporas del patógeno (Figura 5).

Harrison et al. (1997) manifestaron que las zoosporas se sienten fuertemente atraídas por los exudados de las raíces ejerciéndose una quimiotaxis positiva. Mientras que Navia \& García (2004), afirmaron que la estimulación por los exudados radicales parece ser un factor importante en la liberación diferencial de zoosporas primarias en respuesta a distintas variedades de tomate, pues en el ensayo desarrollado por ellos se observó que en el caso de las plántulas de tomate hubo diferencias de la concentración de zoosporas liberadas en tres variedades utilizadas, lo que puede sugerir que algo similar ocurra con diferentes variedades de papa.

Girón \& Robayo (2006) encontraron que hay diferencias en los promedios de liberación de zoosporas en agua, NPK y exudados de las raíces, siendo todos significativamente diferentes, lo cual ratifica los resultados obtenidos en este experimento pues se manifiesta claramente una gran diferencia en cuanto a la liberación de zoosporas entre los sustratos con exudados de raíz, agua y solución nutritiva.

Alzate et al. (2008) encontró mayor liberación de zoosporas en solución de extracto de raíz de papa. Kole (1954), en trabajos con tomate,mostró que la temperatura óptima para la infección de los pelos radicales por S. subterranea es de unos $16-17^{\circ} \mathrm{C}$ y que las temperaturas mínimas y máximas son menores de $11^{\circ} \mathrm{C}$ y $22-25^{\circ} \mathrm{C}$, respectivamente. Navia y García (2004) afirman que a 16 y $20^{\circ} \mathrm{C}$ se observa una gran concentración de zoosporas durante los primeros días, sin embargo conforme pasaban los días, las concentraciones disminuyeron drásticamente y de manera rápida. Álzate et al. (2008) afirma mayor liberación en temperaturas cercanas a $20-23^{\circ} \mathrm{C}$. Todas estas diferencias evidencian los distintos estudios desarrollados bajo condiciones ambientales totalmente disímiles lo que puede intervenir en la respuesta del patógeno. Adicionalmente puede existir una diferencia entre poblaciones de $S$. subterranea halladas en Europa y las encontradas en América como lo sugieren Jaramillo \& Botero (2007).

La utilización de agua y solución nutritiva como sustratos para liberación no obtuvo respuesta significativa debido a que el índice de liberación fue muy bajo sumado a esto era poca la movilidad de las zoosporas y en solución nutritiva se observaba prematuro enquistamiento, sugiriendo así que el efecto de soluciones nutritivas puede ser evaluado conjuntamente con extractos de raíz en trabajos de infección mediante la utilización de plántulas de papa. Donaldson \& Deacon (1993) afirman que las zoosporas pueden ser inducidas al enquistamiento por agentes artificiales, en condiciones de laboratorio puede ser por una alta concentración de químicos o agitación mecánica, lo cual ratifica la teoría del enquistamiento rápido en solución nutritiva en este estudio.

Al comparar los resultados obtenidos para inóculo empleado se observa que las fuentes que arrojaron mejores resultados fueron las obtenidas a partir de tubérculo y raíz, es evidente que sea así debido a que le patógeno cumple su ciclo en este tipo de materiales mientras que en el suelo puede encontrar mayor cantidad de microorganismos que ejerzan presión por competencia y no lo dejen liberar tan rápidamente sus zoosporas, a pesar de todo esto, existe una pequeña diferencia entre las fuentes de tubérculo y raíz la cual se manifiesta las 96 horas donde el tubérculo presenta una mayor liberación de zoosporas con respecto al de raíz (Figura 1).

Así y después de una serie de ensayos de liberación se llega a la conclusión que las mejores condiciones de liberación corresponden a la fluctuación en temperatura $20-15^{\circ} \mathrm{C}$ con inóculo de raíz, requiriéndose un tiempo entre las 24 y 96 horas después de la inoculación para obtener la mayor cantidad de liberación de zoosporas de $S$. subterranea. 
Fuente $=$ Tubérculos

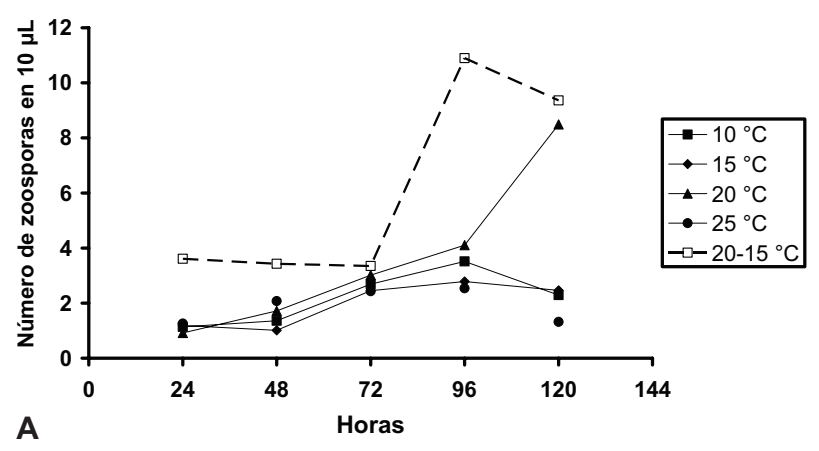

Fuente $=$ Suelo

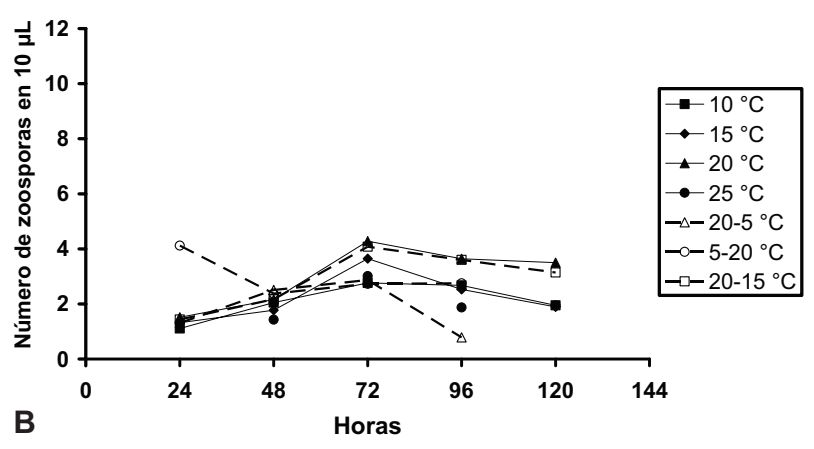

Fuente $=$ Raiz

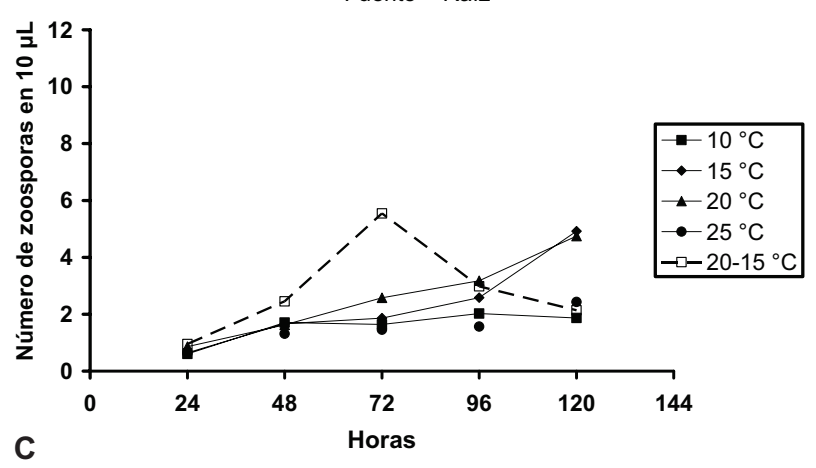

Medio = Solución

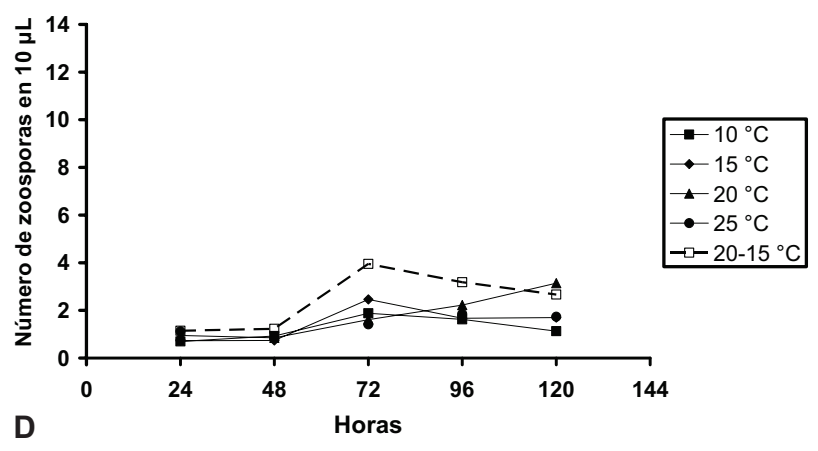

FIGURA 5 - Interacciones observadas en el análisis de los tres ensayos involucrando los factores de tiempo, temperatura, sustrato y fuente de inóculo. A-B-C: Interacción tiempo-temperatura-fuente de inóculo. D-E-F: Interacción tiempo-temperatura-sustrato.

\section{AGRADECIMIENTOS}

Los autores agradecen a Asohofrucol, al Ministerio de Agricultura y Desarrollo Rural por el financiamiento de esta investigación bajo el proyecto 2007S4527-83.

\section{REFERENCIAS}

Alzate DE, Hoyos LM, Gonzalez EP (2008) Factores que inciden en la liberación de zoosporas de Spongospora subterranea
(Wallroth) Lagerheim f. sp. subterranea Tomlinson. Revista Facultad Nacional de Agronomia 61:4503-4510.

Braselton JP (2007) Generalized Plasmodiophorid life cycle based on several sources. Disponible en: http//oak.cats.ohiou.edu/braselto/plasmos/. Acesso en 8 agosto de 2009.

Claxton JR, Arnold DL, Blakesley D (1995) The effects of temperature on zoospores of the crook root fungus Spongospora subterranea f.sp. nasturtii. Plant Pathology 44:765-771.

Cruz M (2008) Sarna de la papa. Informativo No57.Quilamapu Chile. INIA.

Donaldson SP, Deacon JW (1993) Differential encystment 
of zoospores of Pythium species by saccharides in relation to establishment on roots. Physiological and Molecular Plant Pathology 42:177-184.

Falloon RE, Russell AG, Wallace AR, Butler RC (2003) Suceptibility of potato (Solanum tuberosum) cultivars to powdery scab (caused by Spongospora subterranea), and relationships between tuber and root infection. Australasian Plant Pathology 32:377-385.

Girón JA, Robayo NJ (2006) Efecto de los exudados de la raíz de seis cultivares de papa (Solanum tuberosum tuberosum) en la liberación de 39 zoosporas primarias de Spongospora subterranea f. sp. subterranea. Trabajo de grado. Universidad Nacional de Colombia. Bogotá Colombia.

Harrison JG, Searle RJ, Williams NA (1997) Powdery scab disease potato: A review. Plant Pathology 46:7-25.

Hooker WJ (1980) Compendium of Potato Diseases.St. Paul EEUU.APS Press.

Jaramillo S, Botero JM (2007) Respuesta de diferentes poblaciones de Spongospora subterranea f. sp subterranea a la rotación con dos variedades de papa (Solanum tuberosum ssp andigena). Revista de la Facultad Nacional de Agronomía 60:3859-3876.

Karling JS (1942) The Plasmodiophorales: Including a complete host index, bibliography and a description of disease caused by species of this order. New York EEUU. Columbia University.

Kole AP (1954) A contribution to the knowledge of Spongospora subterranean (Wallr.) Lagerh., the cause of powdery scab of potatoes Tijdschrift over Plantenziekten 60:1-65.

Lees AK (2000) Powdery scab: Past and present research. En: Proceedings of the First European Powdery Scab Workshop. Aberdeen Scottland. p. 55-57.

Merz U (1993) Epidemiological aspects of powdery scab of potatoes caused by Spongospora subterranea. Proceedings of the 2nd Symposium of the International Working Group on Plant Viruses with Fungal Vectors. Montreal Canada. p. 104-106.

Millner PD, Kitt DG (1992) The Beltsville method for soilless production of vesicular-arbuscular mycorrhizal fungi. Mycorrhiza 2:9-15.

Navia E, Garcia C (2004) Estudios en la biología y patología de Spongospora subterranea en papa. Revista Latinoamericana de la Papa. Suplemento Especial. p.38.

Torres H (2002) Roña (Spongospora subterranea). pp. 27-31. En: Torres H (ed.) Manual de las enfermedades más importantes de la papa en el Perú. Lima Perú. Centro Internacional de la Papa. pp. 27-31.

Van De Graaf A, Lees AF, Wale SJ, Duncan JM (2005) Effect of soil inoculum level and environmental factors on potato powdery scab caused by Spongospora subterranea. Plant Pathology 54:2228.

Wale S (2000) National potato production and the powdery scab situation. En: Proceedings of the First European Powdery Scab Workshop. Aberdeen Scottland. p. 3-9.

TPP 426 - Recebido 5 Octubre 2011 - Acceptado 4 Junio 2012 Editor de Seccion: Nilceu R.X. Nazareno 